\title{
Justicia y relaciones internacionales: las relaciones hispano-mexicanas (1844-1863)/
}

\author{
Justice and International Relations. \\ Spanish-Mexican Relations (1844-1863)
}

Almudena Delgado Larios

Université Stendhal, Grenoble-3, Francia

En el siglo XIX una de las condiciones esenciales para obtener el reconocimiento de la soberanía de un Estado por parte de la comunidad internacional era la capacidad para mantener el orden interior y garantizar las vidas y propiedades de los súbditos extranjeros. La justicia, entonces, se convierte en un elemento político de primer orden y el caso de las relaciones hispano-mexicanas resulta especialmente significativo. Para México, se trata de preservar la independencia nacional, de evitar una intervención militar y de integrarse en el sistema internacional. Para España, se busca afirmar su estatuto de gran potencia con capacidad para intervenir en defensa de sus ciudadanos y de obtener las debidas reparaciones. Este trabajo se estructura entonces en torno a tres cuestiones: la deuda y las reclamaciones financieras de los españoles, el castigo de los culpables de los asesinatos de españoles y la negociación de un tratado de extradición de delincuentes y desertores.

Palabras Clave: Relaciones España-México; Siglo XIX, Justicia; Extradición; Reclamaciones.

In the nineteenth century one of the key conditions for recognition of sovereignity of a state by the international community was the ability to maintain order and ensure the lives and properties of nationals abroad. Justice, then, becomes a political element of the first order and the case of Spanish-Mexican relations is particularly significant. For Mexico, it is to preserve national independence, to avoid a military intervention and to integrate into the international system. For Spain, it is asserting its status as a great power with the ability to speak in defense of its citizens and to obtain the necessary repairs. This work is structured so on three issues: debt and financial claims of the Spaniards, the punishment of those guilty of the murders of Spaniards and the negotiation of a treaty on extradition of criminals and deserters.

KeYwords: Spain-Mexico; $19^{\text {th }}$ Century; Justice, Extradition; Claims. 
En el siglo XIX, una de las condiciones esenciales para obtener el reconocimiento de la soberanía de un Estado por parte de la comunidad internacional era la capacidad para mantener el orden interior y garantizar las vidas y propiedades de los súbditos extranjeros. A diferencia de la revolución estadounidense, que contó con el apoyo de Francia y de España, las independencias latinoamericanas no obtendrán ni apoyo ni solidaridad por parte de los países europeos. Los principales obstáculos están relacionados con la forma de gobierno adoptada (la república, frente a una Europa exclusivamente monárquica hasta 1848) y con los avatares políticos y financieros de estos países: gran inestabilidad de los gobiernos, enfrentamientos y guerras civiles con sus secuelas de muerte y de destrucción de bienes y propiedades, fuerte endeudamiento. Se cuestiona la capacidad de los gobiernos latinoamericanos para mantener el orden público, proteger a las personas y perseguir y castigar a los delincuentes. En consecuencia, la percepción europea de las nuevas Repúblicas es globalmente negativa y se traduce en una práctica internacional que separa la dimensión política (el reconocimiento de la legitimidad de la independencia y del carácter de Estado plenamente soberano) de la realidad comercial (negociación y ratificación de tratados comerciales).

Gran Bretaña inaugura esta actitud, que implica reservarse la posibilidad de revocar los tratados si se considera que un Estado latinoamericano no respeta la libertad de comercio y navegación o los derechos de propiedad de los súbditos y comerciantes ingleses. Los demás países europeos siguieron globalmente el ejemplo británico hasta bien entrada la segunda mitad del siglo XIX. Se daba, entonces, un reconocimiento parcial de la soberanía republicana, lo que suponía que esos nuevos Estados viviesen con la constante amenaza de caer bajo una nueva dominación europea. No hay que olvidar que en este momento, junto a las campañas colonialistas (destinadas a establecer protectorados o administraciones directas en territorios extra-europeos), las potencias desarrollan una política que ha sido calificada de "imperialismo de libre comercio" (presiones diplomáticas y recurso a la intervención militar para hacer valer sus derechos). ${ }^{1}$ Para los

1 Ya tuve ocasión de mostrar que en lo relativo al "derecho de intervención" de las potencias, no existía un consenso en España y que, por ejemplo, los demócratas de La Discusión diferenciaban Marruecos (donde era legítima la intervención militar con el objetivo de "civilizar") y México (país equiparado a las naciones occidentales y, por tanto, donde no se podía intervenir en defensa de viles intereses materiales -cobrar deudas ilegítimas- o para imponer un sistema político determinado); "La intervención europea en México en la prensa española (1861-1862)", en Fisher, John R.(ed.): Actas del XI Congreso Internacional de AHILA, The Institute of Latin American Studies, University of Liverpool, Liverpool, 1998, 4 vols., vol. III, págs. 58-77. 
nuevos países, la cuestión de la justicia en un sentido amplio (instauración de un Estado de derecho y de instituciones que aseguren la aplicación y el respeto de la ley, tanto en lo relativo a los derechos como a los deberes - y el consiguiente castigo de los infractores-, se convierte entonces en un elemento político de primer orden para preservar la independencia nacional, puesto que la defensa de las vidas y bienes de sus ciudadanos es el argumento utilizado por las potencias europeas para justificar presiones diplomáticas e incluso el recurso a la fuerza.

El caso mexicano es paradigmático a este respecto, particularmente si se estudian las relaciones hispano-mexicanas durante el reinado de Isabel II. Con el tratado que firma con esa República en diciembre de 1836, España inicia el proceso de reconocimiento de las independencias y de acuerdos comerciales. En ese tratado se estipulaba que

los comerciantes y demás súbditos de Su Majestad Católica o ciudadanos de la República Mejicana que se estableciesen, traficasen o transitasen por todo o parte de los territorios de ambos países gozarán de la más perfecta seguridad en sus personas y propiedades y, tanto con respecto a la repartición de contribuciones o impuestos como a la protección y franquicias en el ejercicio de la industria y también en lo relativo a la administración de justicia, serán considerados del mismo modo que los naturales de las respectivas naciones contratantes, sujetos siempre a las leyes, usos y costumbres de aquella en que residan. ${ }^{2}$

Basándose en estas consideraciones de "perfecta seguridad" y de "administración de justicia", España, al igual que los demás países de Europa, se mostrará especialmente celosa a la hora de salvaguardar la vida y los intereses de los españoles residentes en México, lo que dará lugar a un larguísimo conflicto diplomático que en ocasiones derivará en amenazas de recurrir a la fuerza o en intervenciones militares efectivas, como ocurrió entre 1856 y 1862. Entre otros factores, lo que está en juego para España es el ser o no ser considerada gran potencia puesto que son esas grandes potencias, o los países que aspiran a ser considerados como tales, las que se arrogan el "derecho" exclusivo de intervenir en otros invocando esta cuestión de la justicia y del deber de velar por el cumplimiento de la

2 Delgado Martín, Jaime: España y México en el siglo XIX, 3 vols., Instituto "Gonzalo Fernández de Oviedo", CSIC, Madrid, 1950-1953, vol. II, págs. 83-84. Véase igualmente Sánchez Andrés, Agustín: "De la independencia al reconocimiento. Las relaciones hispano-mexicanas entre 1820 y 1836", en Sánchez Andrés, Agustín y Figueroa Esquer, Raúl (eds.): México y España en el siglo XIX. Diplomacia, relaciones triangulares e imaginarios nacionales, Universidad Michoacana de San Nicolás de Hidalgo-Instituto Tecnológico Autónomo de México, México, 2003, págs.23-51. 
ley y de los acuerdos internacionales en lo relativo a la protección de vidas y bienes de los ciudadanos y al pago de la deuda.

Por otra parte, el siglo XIX se caracteriza por la lenta instauración de acuerdos internacionales sobre multitud de cuestiones. Y, entre ellas, dos interesan particularmente al estar directamente relacionadas con el ejercicio de la justicia: la extradición y el derecho de asilo. La primera es un acto mediante el cual un Estado entrega a otro que se lo solicita a un individuo buscado o ya condenado por la jurisdicción penal del país solicitante. La extradición fue, al principio, un simple compromiso de cortesía entre algunos príncipes para obtener la entrega de malhechores de derecho común. En el siglo XVIII la práctica de la extradición se generaliza y se aplica también a los crímenes políticos. Desde entonces y durante el siglo XIX se multiplican las convenciones bilaterales entre los países y los intercambios se intensifican. Sin embargo, el triunfo de las revoluciones liberales conducirá a la progresiva exclusión de los crímenes políticos de los tratados de extradición y a la adopción del derecho de asilo por esos mismos motivos. Como para otros derechos, la Revolución Francesa es el referente obligado al afirmar la Constitución de 1793 el derecho de conceder asilo a los extranjeros perseguidos en sus países por luchar en pro de la libertad y de rechazar ese asilo a los tiranos. Este derecho al asilo se consolidará con las revoluciones liberales a lo largo del siglo XIX y progresivamente los países europeos rechazarán la extradición por motivos políticos.

Habiendo adoptado el régimen republicano, los dirigentes mexicanos asumen la herencia revolucionaria francesa respecto del derecho de asilo y del rechazo de la extradición por motivos políticos. La negociación de un tratado de extradición entre España y México a partir de 1844 refleja esa diferencia profunda entre los regímenes republicanos y los monárquicos plasmada en la cuestión de los delitos políticos, pero constituye al mismo tiempo una vía de integración internacional de México a través del principio de reciprocidad en la concesión de la extradición. Para el gobierno moderado español esta negociación forma parte de una estrategia política con fines internos (preservar el orden político y social establecido y evitar la independencia de Cuba).

Este trabajo se estructura entonces en torno a tres cuestiones: la negociación de un tratado de extradición de delincuentes y desertores entre 1844 y 1847, la cuestión de la deuda y de las reclamaciones financieras de los españoles y, por último, el problema del castigo de los culpables de los asesinatos de españoles en 1856-1857. Sin embargo, estos dos últimos asuntos se 
entremezclan en la coyuntura de 1856 y dan lugar a un momento de gran tensión entre los dos países que se prolongará hasta la intervención tripartita de 1861-1862. De ahí la importancia del relato elaborado en 1855-1856 por los servicios del Ministerio de Estado, donde se explica el origen y el desarrollo de la cuestión de la deuda y donde aparecen los juicios de valor y la visión de las cosas de la diplomacia española en un momento de especial interés puesto que gobiernan los progresistas y que la actitud de firmeza adoptada por ellos será asumida por el primer gobierno del general O’Donnell ${ }^{3}$ en septiembre de 1856. Además, el problema de la deuda condicionará la actitud de los gobiernos españoles ante la cuestión del castigo de los culpables de los asesinatos de españoles en diciembre de 1856. El análisis de la correspondencia diplomática española ${ }^{4}$ permitirá entonces, no sólo conocer el uso político de estos contenciosos por parte de los gobiernos y ver en qué medida se desarrollan una normativa jurídica y una práctica judicial internacionales, sino también estudiar cómo los dirigentes españoles percibían a España y a los "otros" y cuál era la imagen de España en el exterior. Por otra parte, este estudio contribuye a precisar los mecanismos de toma de decisión en política exterior y a mejorar el conocimiento de las redes de relaciones existentes entre los diplomáticos españoles y la clase política mexicana en este periodo.

\section{El tratado de extradición}

Siendo ministro de España en México Pedro Pascual Oliver, ${ }^{5}$ el gobierno español le pide que elabore un proyecto de tratado de extradición

3 Leopoldo O’Donnell y Joris, conde de Lucena y duque de Tetuán (Santa Cruz de Tenerife 1809-Biarritz 1867) fue un general y político español. Tras haberse distinguido en la guerra carlista y haber conspirado contra el general Espartero en 1841, fue nombrado en 1844 capitán general de Cuba. En 1854, junto a otros generales, dirigió la sublevación conocida como la Vicalvarada, cuyo triunfo dio paso al bienio progresista, durante el cual O'Donnell fue ministro de la Guerra y luego presidente del Gobierno. Tras un tiempo alejado del poder (1856-1858) volvió a ocupar la presidencia al frente de la Unión Liberal (1858-1863), periodo durante el cual se desarrollaron las llamadas "acciones de prestigio" (guerra de África, anexión de Santo Domingo, intervención tripartita en México).

4 Se trata de la correspondencia que se encuentra en la sección "Tratados y negociaciones siglo XIX" correspondiente a México.

5 Para una presentación y un estudio de la acción de los diplomáticos españoles en México en este periodo véase mi trabajo "Diplomáticos en acción: fuerza y fragilidad de los agentes de la política exterior española en el caso mexicano (1840-1856)", en Navarro Antolín, Fernando (ed.): Orbis Incognitus. Avisos y legajos del Nuevo Mundo. XII Congreso Internacional de la AEA, Universidad de Huelva, Publicaciones-Asociación Española de Americanistas-Junta de Andalucía, Consejería de Innovación, Ciencia y Empresa, Collectanea 130, Huelva, 2008, págs. 905-914. 
en junio de $1844 .^{6}$ Hacía un mes que presidía el gobierno el general Narváez y ocupaba la Secretaría de Estado el marqués de Viluma. ${ }^{7}$ Para entender esta iniciativa y la importancia dada a esta negociación, hay que recordar que en 1842 se han producido rebeliones de esclavos en Cuba y que en 1844 precisamente ha tenido lugar la rebelión conocida como de "La Escalera" ferozmente reprimida por las autoridades españolas, siendo en ese momento Leopoldo O'Donnell capitán general de Cuba. Los hacendados cubanos, incluidos los anexionistas como Domingo del Monte, confían en Francisco Martínez de la Rosa y en el gobierno moderado para reprimir las rebeliones negreras y mantener la esclavitud. ${ }^{8} \mathrm{El}$ argumento esgrimido, ante las autoridades españolas pero también ante Estados Unidos, es que los ingleses, "cansados en su intento de garantizar la abolición del tráfico de esclavos, tenían la intención de apoderarse de Cuba, liberar a los negros y establecer una república militar negra bajo protección británica". ${ }^{9}$ Por otra parte son numerosos los desertores de la Marina española que buscan refugio en México y las autoridades únicamente aceptan devolver a los simples marinos pero no así a los oficiales. ${ }^{10}$

El 24 de octubre de 1844 envía Oliver su proyecto, que consta de cinco artículos. En el artículo primero se establece el tipo de crímenes concernidos por el convenio, siendo todos ellos delitos comunes (crímenes con derramamiento de sangre, robos con violencia, incendios premeditados, falsificación de moneda), sin ninguna mención a delitos políticos. Por otra parte, el artículo segundo aclara que la extradición supondrá la conmutación de la pena de muerte por la pena más inmediata inferior, salvo en el caso de los parricidas. El artículo cuarto incluye a los marineros desertores,

6 Archivo Histórico del Ministerio de Asuntos Exteriores de España (AMAE), Tratados Negociaciones siglo XIX, n. ${ }^{\circ}$ 0332-01 Justicia, TR211, expediente 007. Este expediente es la fuente fundamental para elaborar este apartado y, para no multiplicar las notas, sólo se volverá a citar cuando se haya incluido entre medias una nota aclaratoria o relativa a otra referencia.

7 Manuel de la Pezuela Ceballos, marqués de Viluma, será ministro de Estado del 3 de mayo al 1 de julio de 1844, luego ocupará interinamente el cargo el mismo Narváez, entre el 1 de julio y el 21 de agosto, hasta la llegada de Martínez de la Rosa, que será ministro del 21 de agosto de 1844 hasta el 12 de febrero de 1846 .

8 Piqueras, José A.: Sociedad civil y poder en Cuba. Colonia y poscolonia, Siglo XXI, Madrid, 2005, pág. 116.

9 Carta de uno de los hacendados cubanos exiliados después de "La Escalera", Domingo del Monte, al secretario de Estado de Estados Unidos, Daniel Webster, en Thomas, Hugh: Cuba. La lucha por la libertad, Editorial Debate, Barcelona, 2005 ( $1^{\circ}$ edición, 2004), pág. 174.

10 AMAE, Tratados Negociaciones siglo XIX, TR211, 007, Primera Secretaría de Estado y del Despacho, Palacio, 28 de enero de 1844 a agosto de 1846. 
pero no se especifica si se aplica igualmente a los oficiales de Marina. El artículo tercero establece que los gastos de encarcelamiento, manutención y extradición correrán a cuenta del país solicitante y el último artículo fija los plazos de entrada en vigor. Oliver considera que no habrá dificultades para que México acepte los términos del tratado que él propone.

$\mathrm{Y}$ en efecto, este proyecto, al excluir los delitos políticos y al establecer el principio de la sustitución de la pena de muerte por otra pena inferior, asume los avances de la revolución liberal. Así lo reconoce la mesa de la Primera Secretaría de Estado y del Despacho cuando se refiere "a las costumbres del día que repugnan la entrega de reos por delitos políticos". Pero la misma mesa añade que existen consideraciones particulares que permitirían incluir los delitos políticos. Se trata de la cuestión de la cercanía de México respecto de las Antillas españolas y de la comunidad de idioma y de costumbres que alentarían los proyectos de fuga de los criminales. La mesa propone incluir en el tratado a los reos de conspiraciones independentistas y de rebeliones negreras alegando que se trata de delitos de alta traición y no de delitos políticos. La mesa considera igualmente que no debe aplicarse el artículo segundo que reduce la pena de muerte. Por último, opina que es el momento propicio por encontrarse México en plena convulsión política y aconseja "celebrarlo con cualquier jefe de gobierno que dominara en la República (...) porque nunca está más dispuesto un gobierno a celebrar cierta clase de tratados que en sus momentos de más debilidad en que acepta los convenios como prueba de estabilidad propia y reconocimiento hacia las Potencias que se acercan a ellos considerándolos fuertes". Y termina diciendo que no hay peligro de que la opinión pública mexicana se indigne porque ésta no existe y porque la extradición no contraría los intereses mexicanos. La Junta consultiva considera que no será posible incluir los delitos políticos por hallarse imbuido el nuevo gobierno mexicano "en las paradojas de la Revolución Francesa".

Oliver será sustituido por Salvador Bermúdez de Castro y el estudio de su gestión confirma lo acertado de la opinión de la mesa de la Secretaría de Estado relativa a la conveniencia de aprovechar las coyunturas de inestabilidad gubernativa de un país para conseguir firmar tratados favorables. El nuevo ministro plenipotenciario español en México se ocupa del convenio de extradición, además de favorecer el proyecto de instauración de una monarquía en México y de firmar un convenio sobre la deuda. El balance de su gestión es muy positivo para España, aunque las ventajas obtenidas 
sean más o menos duraderas según los casos. ${ }^{11}$ El 20 de julio de 1845, la Secretaría de Estado le envía instrucciones y le otorga la plenipotencia para negociar y concluir el convenio de extradición. Recordemos que preside el Consejo de ministros el general Narváez y que es ministro de Estado Francisco Martínez de la Rosa. En ese documento aparece claramente explicitado el problema que plantea el tratado de extradición: por un lado está el fin, "destruir hasta la presunción de impunidad a los malévolos de nuestras Antillas"; por otro, las ideas del siglo "rechazan la extradición por delitos políticos, con cuyo colorido se desfiguran hoy crímenes que antes de ahora jamás se han calificado de tales". ${ }^{2}$ Por ese motivo, el gobierno le encomienda que procure "por cuantos medios estén a su alcance, intercalar otro [artículo] público o secreto" para que sean considerados reos de alta traición los complicados en conspiraciones negreras en cualquiera de los dominios de España y los que resulten criminales en causas sobre emancipación de las colonias españolas" y que sean comprendidos en la extradición sin la garantía de la conmutación de la pena de muerte. El ministro de Estado dice claramente que el objetivo principal de la negociación para llegar a un convenio con México es la extradición de esa clase de criminales. Es tal la prioridad, que el mismo especifica que Bermúdez de Castro debe de asegurarse de que el gobierno mexicano aceptará incluir ese artículo sobre la extradición por delitos políticos antes de iniciar las conversaciones. Se le autoriza a emplear medios extraordinarios para vencer repugnancias o escrúpulos y se pone a su disposición un buque de guerra. El gobierno español recuerda que las relaciones entre los dos países son buenas en ese momento y que España acaba de dar pruebas de ello en la cuestión de Texas y cuenta también con la buena disposición de las personas que componen el gobierno mexicano. De ahí que España considere que es el momento más oportuno para iniciar esta negociación.

Bermúdez de Castro subraya la dificultad que plantea la exigencia del gobierno español de conseguir incluir la extradición por motivos políticos y sin conmutación de la última pena, no sólo por ir contra las ideas gene-

11 En el caso de la conspiración monárquica, si bien el general Paredes accede momentáneamente al poder, será barrido por un movimiento federalista pocos meses después, en agosto de 1846, por lo que no se llegó a reunir el congreso que debía pronunciarse a favor del régimen monárquico. En cuanto al convenio de la deuda, firmado en 1847, las autoridades mexicanas lo cuestionarán pero lo aplicarán parcialmente hasta inicios de la década de 1850 . En cuanto al convenio de extradición, no llegó a ser ratificado por México, como consecuencia de la victoria federalista.

12 AMAE, Tratados-Negociaciones siglo XIX, TR211, 007, Estado a ministro plenipotenciario en México, Madrid, 20 de julio de 1845. 
rales del siglo, sino por las circunstancias particulares que presenta la República Mejicana al ser antigua colonia española "que trae su origen como nación de un levantamiento contra la metrópoli" por lo que no pueden entregar a la muerte a los reos de un crimen a que debe su existencia. ${ }^{13}$ A esto se añade la abolición de la esclavitud que figura en la Constitución mexicana. El diplomático añade una consideración económica a éstas de índole jurídico-política: en Yucatán y Tabasco, la emigración de negros y de criminales políticos cubanos proporciona mano de obra, industrias y capitales. Y prosigue ensombreciendo aún más el panorama al recordar la "falta absoluta de decisión, de facultades del Gobierno" mexicano y el extraordinario poder que poseen las Cámaras. Y, por último, dice el ministro plenipotenciario, la misión es todavía más difícil al no poder permanecer en secreto el convenio, de llegar a firmarse. A través de estas apreciaciones, trasluce la condena del sistema republicano (en este caso de la República centralista Mejicana, que atravesaba una fuerte inestabilidad). No hay que olvidar que el mismo Bermúdez de Castro estaba organizando una conspiración para instaurar la monarquía en México. ${ }^{14}$ Éste proclama que, a pesar de estas dificultades, empleará todos los recursos y toda la influencia que estén a su alcance para conseguirlo. Indica que por ello no intentara trabajar con el ministro de Relaciones Exteriores, "hombre tímido, indeciso y nada reservado en los negocios, si bien honrado y dispuesto a favor de España", sino que quiere asegurarse la opinión de algún hombre de conocida influencia a quien pueda hacer nombrar Plenipotenciario. Este personaje es Valdivieso, ministro mexicano en España que se encuentra en México. Bermúdez de Castro aprovecha la coyuntura de conflicto con Estados Unidos por la cuestión de Texas y de tensiones con Francia, para presentar a España como potencia amiga de México. Para intentar convencer a Valdivieso, el diplomático español utiliza los siguientes argumentos: México se beneficiaría, al igual que España, puesto que los criminales también pueden refugiarse en las Antillas españolas; a la inversa, si los independentistas antillanos y los negros que quieren sublevarse encuentran refugio en México, se podría proclamar una república negra que pondría en peligro los Estados de Yucatán y de Tabasco. Paralelamente, el diplomático español intenta convencer al ministro de Relaciones Exteriores, Manuel de la Peña, de que acepte el convenio.

13 Ibidem. Salvador Bermúdez de Castro a Estado, México, n 118, 26 de septiembre de 1845.

14 Soto, Miguel: La conspiración monárquica en México, 1845-1846, EOSA, México, 1988; Delgado, Jaime: La monarquía en México, Porrúa, México, 1990. 
Un incidente va a favorecer los planes españoles: Antonio López de Santa Anna ${ }^{15}$ confía al senador Rafael Canalizo que un tal Gómez ha intentado asesinarlo y que implicaba al senador Manuel Gómez Pedraza. El presidente Herrera y su gobierno solicitan a las autoridades españolas de Cuba que proporcionen toda la información posible sobre este asunto y Bermúdez de Castro aprovecha la ocasión para plantear la necesidad de un tratado de extradición. ${ }^{16}$ El 28 de noviembre de 1845, cuando el general Paredes está a punto de sublevarse contra el gobierno de Herrera, con el apoyo del mismo Bermúdez de Castro, el ministro español en México envía el proyecto de tratado de extradición. ${ }^{17}$ En su informe, explica que para la elaboración de dicho proyecto ha leído tratados y convenios semejantes, examinando con especial detenimiento los celebrados por España. Cuando cita los casos concretos se comprueba que se trata de convenios del siglo XVIII (con Francia en 1765; con Portugal en 1778; con la República de Génova en 1779), anteriores por tanto a la Revolución Francesa y a los principios liberales. Reconoce haber estudiado los convenios con Dinamarca, Holanda y Portugal de 1767, 1791 y 1823 pero "ni son tan explícitos como los anteriores, ni contienen las ideas de latitud en la extradición que yo quería en todo caso hacer valer como autoridades y ejemplos para mi propósito". En realidad, la estrategia de Bermúdez de Castro consiste en partir de un concepto muy amplio de extradición para poder dar la impresión de negociar y, por tanto, de renunciar, a ciertos aspectos pero salvando el objetivo primordial de incluir los delitos de conjuraciones negreras y de sedición en las posesiones ultramarinas españolas.

El proyecto contempla en sus dos primeros artículos el caso de los delincuentes comunes: tanto si cometen el delito en un país y se refugian en el otro, como si lo cometen en el suyo propio pero huyen igualmente, serán presos y entregados al gobierno en cuyo territorio haya tenido lugar el delito o donde estaban presos. Dicha entrega se hará por requisición de un gobierno a otro por medio de sus representantes o por exhorto documentado de la autoridad judicial competente (artículo $3^{\circ}$ ). Los artículos cuarto a séptimo contemplan el caso de los delitos políticos. El cuarto y el quinto

15 Antonio de Padua María Severino López de Santa Anna y Pérez de Lebrón (21 de febrero de 1794-21 de junio de 1876), político y militar mexicano, fue presidente de México en once ocasiones entre 1833 y 1855 . Este periodo coincide con la época de los "agiotistas" y con la pérdida de Texas y la guerra con los Estados Unidos, que hizo perder a México gran parte de su territorio.

16 AMAE, Tratados-Negociaciones siglo XIX, TR211, 007, Salvador Bermúdez de Castro a Estado, México, $\mathrm{n}^{\circ} 142,29$ de octubre de 1845.

17 Ibidem. Salvador Bermúdez de Castro a Estado, México, n 162,28 de noviembre de 1845. 
se refieren, respectivamente, a los reos de delito de sedición y de fomento de la independencia y a los reos en conjuraciones negreras. Se cita el artículo secreto adicional al Tratado de $1836 .{ }^{18} \mathrm{El}$ artículo séptimo se refiere a los sediciosos mexicanos refugiados en las posesiones españolas: serán primero internados a la mayor distancia posible de la costa y en segundo lugar expulsados. En cuanto a los desertores, ambas naciones se comprometen a entregarlos. El artículo octavo especifica que se entregarán los delincuentes mencionados aun cuando se hayan acogido a la inmunidad eclesiástica pero, para respetar los convenios eclesiásticos, la restitución y el castigo se harán en función de las legislaciones respectivas.

El triunfo de la revolución del general Paredes no entorpece la gestión del ministro español, que consigue que Manuel de la Peña siga siendo el plenipotenciario mexicano encargado de la negociación. ${ }^{19}$ Bermúdez de Castro se vanagloria de haber conseguido la firma del plenipotenciario mexicano en su despacho del 28 de junio de 1846 . El proyecto ha cambiado un poco en un sentido más duro puesto que entre los crímenes ordinarios se incluye el de robo de caudales públicos y, en cuanto a los delitos políticos, se establece que afecta a aquellas personas que hubieren cometido o intentado cometer delitos de sedición en las posesiones españolas, o promovido trastornos. No se respetaba totalmente la reciprocidad puesto que los conspiradores mexicanos que se refugiaran en las colonias españolas no serían entregados a México sino tan sólo alejados de las costas. Toda esta negociación transcurre en medio del estallido de la guerra por Texas. Tan satisfecho se muestra Bermúdez de Castro que solicita que se le con-

18 En este artículo secreto, México se comprometía a impedir y reprimir todo acto que se dirija contra las posesiones españolas y en el caso de que se introdujeran en México conspiradores o partidarios de la independencia de las colonias españolas a alejarlos de los puertos mexicanos. España se comprometía a hacer lo mismo respecto de México; Delgado Martín, Jaime: España y México..., vol. II, págs. 120-121.

19 Teniendo en cuenta la figura de Manuel de la Peña y Peña (Ciudad de México, 1789 Ciudad de México, 1850) se entiende que Bermúdez de Castro insista para que siga siendo él el plenipotenciario. Abogado civil y eclesiástico desde diciembre de 1811, fue síndico del Ayuntamiento de la Ciudad de México desde diciembre de 1813. En febrero de 1820 se le designó oidor de Quito pero ante la proclamación del Plan de Iguala, prefirió quedarse en México y a partir de ese momento ocupó cargos importantes. En 1824 fue nombrado ministro de la Suprema Corte de Justicia de la Nación; con Anastasio Bustamante como presidente, fue ministro del Interior. En 1843 redactó un Código Civil y participó en las Bases Orgánicas de la Junta Nacional Legislativa. Fue profesor de la Universidad, presidente de la Academia de Jurisprudencia y rector del Colegio de Abogados. En 1845 se le designó ministro plenipotenciario en Roma. Del 14 de agosto al 13 de diciembre de 1845 fue ministro de Relaciones Interiores y Exteriores en el gobierno de José Joaquín de Herrera. Jurista y político, fue también presidente interino de México en dos ocasiones durante la Guerra de Intervención Norteamericana. 
ceda a Manuel de la Peña la Gran Cruz de Carlos III, recordando que fue oidor de la Audiencia de México y asesor del Virreinato.

El proyecto será ratificado por España pero entre tanto la situación política mexicana cambió puesto que el triunfo del general Paredes fue breve y los federalistas volvieron al poder. En octubre de 1846, Bermúdez de Castro informa que ahora dominan las ideas ultra democráticas, por lo que es imposible obtener la aprobación de un convenio tal y como se había firmado con Manuel Peña y Peña, "La extradición por delitos políticos es objeto de odio especial para el sistema dominante". ${ }^{20}$ El ministro español cuenta sin embargo con la inestabilidad política mexicana para conseguir esa ratificación por parte de México, aunque es consciente de los peligros que dicha inestabilidad entraña. En efecto, "los gobiernos duran menos que el cambio de los correos de Europa y, en medio de tantos y tan continuos apuros para los que mandan, la diplomacia, sólo por medio de golpes de mano puede conseguir el arreglo de los negocios". ${ }^{21}$ Está claro que sólo sería posible con un sistema dictatorial, como reconoce el mismo Bermúdez de Castro.

El tratado no se ratificó y habrá que esperar a la década de 1880 para que se firme un convenio de extradición entre los dos países pero en el que no se contemplan ya los delitos políticos. En efecto, a partir de 1848 y aunque se repitan situaciones de debilidad para los gobiernos mexicanos, no se volverá a plantear la posibilidad de incluir los delitos políticos en un tratado con España, por lo que se puede decir que los dirigentes mexicanos lograron reafirmar su posición internacional de Estado independiente y soberano apoyándose en los principios liberales y adaptándolos a los asuntos judiciales para propiciar un cambio sustancial de concepción: de la extradición por delitos políticos se pasa al derecho de asilo por motivos políticos.

\section{Deuda y reclamaciones}

Antonia Pi-Suñer ha analizado la cuestión de la deuda española en México entre 1821 y 1890 y ha detallado las presiones de los acreedores españoles, el peso de las consideraciones de honor por parte de España y el comportamiento de los distintos actores, los dirigentes mexicanos y españo-

20 AMAE, Tratados-Negociaciones siglo XIX, TR211, 007, Salvador Bermúdez de Castro a Estado, México, n 363, 26 de octubre de 1846.

21 Ibidem. 
les. ${ }^{22}$ Lo que nos interesa aquí es analizar la visión del servicio diplomático español en dos momentos muy interesantes para las relaciones hispano-mexicanas. En efecto, el negociado del Ministerio de Estado traza el ocho de junio de 1855 el largo historial de este contencioso que opone a España y a México. ${ }^{23}$ Es interesante destacar que en ese momento el oficial del Negociado es Mariano Díaz del Moral y que el director del mismo no es otro que Miguel de los Santos Álvarez, que será nombrado ministro plenipotenciario en México en 1856. En el mismo expediente se encuentra un nuevo relato de los mismos hechos fechado en Palacio el 29 de noviembre de 1856. La primera fecha corresponde al periodo de gobierno progresista tras el triunfo de la revolución en 1854, que genera un cambio de personal y obliga de alguna manera a sintetizar el problema y a hacer un balance de lo acaecido desde el inicio de esta cuestión. La segunda fecha corresponde a la vuelta al poder del general Narváez tras el breve gobierno de O’Donnell en el verano e inicios del otoño de $1856 .{ }^{24}$ Aunque los dos relatos coinciden en lo general, se aprecian diferencias en la valoración y percepción de los hechos y de la política a seguir.

En esos dos textos se puede ver cómo los problemas se dan independientemente de la orientación ideológica de las administraciones mexicanas puesto que los conservadores como Santa Anna acceden a revisar los acuerdos en momentos de debilidad pero no por ello pagan por los problemas de inestabilidad política. La administración española es plenamente consciente de la complejidad de la cuestión y de las dificultades inherentes a ella: "Parecía que el negocio de que se trata estaba destinado a ser la piedra de toque en que se ensayara la habilidad de los representantes españoles". ${ }^{25}$

22 Pi-Suñer Llorens, Antonia: La deuda española en México. Diplomacia y política en torno a un problema financiero, 1821-1890, El Colegio de México-UNAM, México, 2006.

23 AMAE, Tratados Negociaciones siglo XIX, $\mathrm{n}^{\circ}$ 156, TR 102, expediente 001, El negociado de América sobre la cuestión de Méjico, Madrid, Palacio, 8 de junio de 1855.

24 El general O'Donnell gobierna del catorce de julio al doce de octubre de 1856 (ocupando el puritano Nicomedes Pastor Díaz la cartera de Estado) y el general Narváez del doce de octubre de ese mismo año al quince de octubre de 1857 (siendo ministro de Estado el marqués de Pidal).

25 AMAE, Tratados Negociaciones siglo XIX, TR 102, 001, El negociado de América sobre la cuestión de Méjico, Madrid, Palacio, 8 de junio de 1855. Teniendo en cuenta esta reflexión y desde la óptica española, Salvador Bermúdez de Castro, el marqués de la Ribera (con matices) y Juan Antoine y Zayas se ilustrarían positivamente puesto que consiguieron negociar convenios: el de 1847, el de 1851 y el de 1853, aunque todos ellos fueron cuestionados y rechazados por los mexicanos poco tiempo después de haber sido aceptados. He realizado un estudio de las condiciones en las que se debía desenvolver la acción de los representantes diplomáticos españoles en México (escasez de la dotación presupuestaria de la legación, atrasos en los pagos de los sueldos de los diplomáticos, lo que favorece la confusión entre los intereses individuales y personales de estos últimos y los intereses nacionales españoles, pero también la importancia de las redes de relación con la clase política mexicana) en "Diplomáticos en acción: fuerza y fragilidad...", citado en nota 5. 
Para el oficial, todos los problemas y las tensiones entre España y México (la última como consecuencia de la negativa del gobierno de México de recibir al ministro plenipotenciario español Juan Antoine y Zayas) están íntimamente entrelazados con el problema "que tiene erizadas de dificultades las relaciones entre ambos países: la cuestión de las reclamaciones españolas contra el erario de Méjico para cuyo pago se han concluido hasta ahora tres convenios sin que se haya conseguido aún establecer una marcha regular exenta de complicaciones". Para comprender esta dificultad el negociado recuerda el estado de anarquía en que se encuentra el país casi desde su independencia, lo que provoca que se atiendan prioritariamente las cuestiones internas en detrimento del cumplimiento de las estipulaciones internacionales. Por otra parte, dice el oficial, cada nuevo gobierno mexicano niega validez a las disposiciones adoptadas por el anterior. Por último, atribuye igualmente una gran parte de la responsabilidad a los españoles que negociaron el tratado de 1836. En efecto, en su opinión, España no sólo perdió la oportunidad de obtener ventajas económicas, sino que no se estipuló la exención para los residentes españoles de los empréstitos forzosos y, lo más grave, se redactó de manera dudosa el artículo séptimo por lo que no se sabía si el Gobierno español podía o no intervenir para que fuesen pagados los créditos procedentes de dicha deuda. Para el oficial, los que negociaron dicho tratado en 1836 dejaron de asegurar las ventajas a las que España podía y debía aspirar por su especial situación respecto de México y por su identidad de origen, religión y costumbres. Esta idea de la identidad "cultural" (origen, religión, idioma, costumbres) se reitera en el relato de noviembre de 1856, pero se añade la noción de "derechos que disfrutan en todas las Naciones los extranjeros". ${ }^{26}$

En realidad, la deuda contraída por el Gobierno de la metrópoli en México hasta la independencia se consideró como nacional mexicana (España precisamente condicionó el reconocimiento de las independencias a la aceptación por las nuevas autoridades de las Repúblicas de esa deuda como propia) y era entonces lógico que las autoridades españolas no pudieran intervenir, además se habían comprometido en 1836 a no hacerlo. ${ }^{27} \mathrm{El}$

26 AMAE, Tratados Negociaciones siglo XIX, TR 102, 001, El negociado de América sobre la cuestión de Méjico, Madrid, Palacio, 29 de noviembre de 1856.

27 El artículo séptimo del Tratado de 1836 estipulaba que "la República Mejicana y S.M. Católica, por sí y sus herederos y sucesores, de común conformidad, desisten de toda reclamación o pretensión mutua que sobre los expresados puntos pudieran suscitarse y declaran quedar las dos Altas Partes contratantes libres y quitas, desde ahora y para siempre, de toda responsabilidad en esta parte"; Pi-Suñer Llorens, Antonia, La deuda española en México..., pág. 60. 
problema surge por el hecho de que se acaban mezclando diferentes asuntos (esa deuda anterior a la independencia y la nueva como consecuencia de los empréstitos más o menos forzosos obtenidos por los sucesivos gobiernos mexicanos de los particulares, mexicanos y extranjeros) y que se negocian otros convenios. Por otra parte, en 1856 incide mucho más que en anteriores ocasiones la cuestión del prestigio y del estatuto de España como potencia europea, es decir, superior a México en categoría internacional, y por ello con derecho a recibir el mismo trato y a obtener idénticas ventajas que Francia e Inglaterra. Esto confirma la voluntad de los dirigentes españoles de llevar a cabo una política exterior más activa.

La "nacionalidad" es la clave de este asunto: en primer lugar hay que determinar si es deuda nacional — mexicana - o no —en este caso española-; en segundo lugar, en el caso de ser considerada deuda española y no mexicana, hay que demostrar que los créditos incluidos son "españoles" tanto en el origen como en la evolución posterior (que los bonos siguen en manos de ciudadanos no mexicanos). De esta determinación de si se es o no mexicano o español depende la solución judicial del problema de la deuda y el que sean tribunales civiles mexicanos los que se pronuncien o, al contrario, intervengan las instancias diplomáticas y los convenios o tratados internacionales. Y esta distinción tiene importantes repercusiones en el terreno judicial puesto que los litigios relativos a la deuda nacional mexicana se dirimen en los tribunales civiles y según el Derecho común, mientras que los relativos a la deuda española se rigen por los tratados internacionales. De ahí que para las autoridades españolas sean decisivas las negociaciones de los diferentes convenios.

Precisamente esos "otros" convenios fueron tres. En primer lugar el de 1847, que era muy ventajoso para España y los acreedores españoles. El mismo negociado reconoce que Bermúdez de Castro lo logró por la influencia que tenía en aquel entonces y por la situación de debilidad de México, en plena guerra con Estados Unidos, pues de otro modo "habría sido muy difícil inducirle a aceptar obligaciones que podía eludir escudándose en el artículo séptimo del Tratado de 1836 ". ${ }^{28}$ Ese convenio creaba "un fondo considerable, seguro y exclusivo para atender al pago de las reclamaciones españolas", y en virtud del mismo se creo una Junta de cinco personas nombradas por el ministro plenipotenciario español para administrar ese fondo. ${ }^{29}$

28 AMAE, Tratados Negociaciones siglo XIX, TR 102, 001, El negociado de América sobre la cuestión de Méjico, Madrid, Palacio, 8 de junio de 1855.

29 Ibidem. Madrid, Palacio, 29 de noviembre de 1856. 
Luego se llegó al convenio de 1851, negociado por Juan Antoine y Zayas y, finalmente, al tratado de 1853 negociado por el marqués de la Ribera con Antonio López de Santa Anna. Los funcionarios españoles insisten en mostrar la paciencia y la buena fe de España, que acepta en todas estas ocasiones modificar los términos de lo acordado previamente: fue el caso de Ramón Lozano, encargado de negocios en ausencia de Bermúdez de Castro y a la espera de la llegada del nuevo ministro, cuando aceptó que el fondo especial creado por el recientemente firmado convenio de 1847 no se aplicara a la amortización de la deuda anterior a la independencia y que se pasara del 3\% al 2\% sobre el producto de las aduanas mexicanas. Al llegar finalmente el nuevo ministro plenipotenciario, Juan Antoine y Zayas, las autoridades mexicanas declaran nulo el convenio de 1847, aunque las negociaciones posteriores y la firma del convenio de 1851 suponen el reconocimiento implícito del convenio de 1847. Por dicho convenio de 1851 se ponía fin al fondo especial creado por Bermúdez de Castro y se establecía el pago mediante bonos del tesoro que ganarían un interés del $3 \%$ pagaderos por semestres en metálico con exclusión de todo papel.

El negociado cuenta que se empezó a pagar la deuda pero que enseguida se presentó una grave dificultad. Fernando Ramírez, ministro de Estado mexicano, fue acusado en la prensa y en las Cámaras de haberse excedido en sus facultades con grave perjuicio de los intereses públicos al firmar el convenio de 1851. En efecto, una de las principales consecuencias era que reconocía como exterior una deuda que era nacional en virtud del tratado de 1836. Esta circunstancia le permite al funcionario español referirse de nuevo a los desastrosos términos del artículo séptimo del tratado de 1836. El relato de noviembre de 1856 añade un dato de interés: ante las reacciones mexicanas en contra de Fernando Ramírez y del convenio, Zayas propuso que se incluyera un artículo secreto que considerara el artículo séptimo de la misma manera que México, es decir, reconociendo como deuda mexicana toda la que pesaba sobre las cajas de la Nueva España en el momento de la independencia. Esta decisión no podía ser bien acogida por las autoridades españolas y, aunque no se dice explícitamente que fuera la causa de su cese, el gobierno español separó del servicio a Antoine y Zayas poco después. En 1851-1852 se nombró al marqués de la Ribera, el cual tuvo que afrontar los mismos obstáculos que sus predecesores puesto que, una vez más, el gobierno mexicano declaró nulo el convenio que acababa de firmarse, el de 1851, como con anterioridad lo había hecho respecto del de 1847. Mariano Díaz del Moral recalca que se trata 
del tercer convenio y que se habían perdido seis años de negociaciones. El marqués de la Ribera "defendió con todo empeño la validez del Convenio" $30 \mathrm{y}$, tras apurar todos los recursos para conseguir su cumplimiento, tomó una decisión que no será aprobada por el gobierno español y que le costará el cargo: la ruptura de relaciones. Sin embargo, entre el cese decretado por el gobierno y la decisión de nombrar a un nuevo representante, el marqués de la Ribera consiguió que México firmara un nuevo convenio, elevado a la categoría de tratado, el de $1853 .{ }^{31} \mathrm{Si}$ en el relato de 1855 no se comenta nada sobre las ventajas para España, en el de 1856 se aclara que en él se conceden a los acreedores españoles ventajas que no les habían dado ninguno de los convenios anteriores. Se entiende mejor la obstinación de todos los gobiernos españoles a partir de ese momento para que México respete lo estipulado en ese tratado.

Al ser el marqués destinado a Berlín, se nombra ministro plenipotenciario a Ramón Lozano. Sin embargo, se dice en 1855, "no habían transcurrido ni tres meses tras la firma del tratado de 1853 que el gobierno mexicano faltó a ella". ${ }^{32}$ El negociado aclara que la penuria del erario mexicano permite comprender que se distrajera el dinero del Tratado para otras cosas porque, como las rentas del erario mexicano se reducen casi a las de las aduanas y el $40 \%$ de éstas se destina al pago de diferentes convenios de deuda, sólo queda un $60 \%$ para el servicio público. Y el mismo funcionario señala que fue un error atribuir el $8 \%$ al pago de las reclamaciones en vez de establecer una tasa más reducida, que habría facilitado el abono. En 1856 se incluye una reflexión sobre el incumplimiento considerándolo lógico puesto que no se habían cumplido los anteriores convenios, que eran menos gravosos para la hacienda mexicana.

Entre tanto la cuestión se complica por la separación de Ramón Lozano del cargo de ministro plenipotenciario. El motivo del cese no es otro que el de haberse implicado en los asuntos de la Junta de acreedores que había sido creada por Bermúdez de Castro para ocuparse de la gestión del pago de la deuda española, faltando así a las instrucciones del gobierno español que exigía que el representante diplomático no interviniera para nada en la distribución de los fondos y en el funcionamiento de la Junta.

30 Ibidem. Madrid, Palacio, 8 de junio de 1855.

31 El marqués de la Ribera anunció la ruptura de relaciones el dos de septiembre de 1853 y el nuevo tratado fue firmado el doce de noviembre del mismo año.

32 AMAE, Tratados Negociaciones siglo XIX, TR 102, 001, El negociado de América sobre la cuestión de Méjico, Madrid, Palacio, 8 de junio de 1855. 
Este incidente es en realidad la clave de los acontecimientos posteriores y marca una ruptura con todo el periodo anterior. En efecto, las disensiones entre acreedores se traducen en acusaciones mutuas de haber incluido créditos ilegítimos en el tratado de 1853 y en los anteriores convenios, especialmente en el de $1851 .{ }^{33}$ El gobierno mexicano, que como en otras ocasiones había dejado de pagar, aprovecha la oportunidad para pedir la revisión del conjunto de los créditos, lo que le permitiría reequilibrar la cuestión a su favor, aprovechando la favorable coyuntura que le proporcionan los acontecimientos políticos españoles (caída de los moderados, revolución de 1854 y llegada al poder de los progresistas). Las autoridades españolas, por su parte, piensan seguramente lo mismo de la situación mexicana puesto que en marzo de 1854 ha estallado la revolución de Ayutla de los liberales contra Santa Anna. Se plantea entonces al gobierno español la estrategia que hay que adoptar. Según el funcionario, en 1855, el gobierno mexicano debe establecer una lista de los créditos que considera ilegítimos y aportar las pruebas de dicha ilegitimidad para que el gobierno español se pronuncie al respecto. Esta solución es la más ventajosa para España puesto que se evita una revisión global de todos los créditos o la necesidad de negociar un nuevo acuerdo. Aparece ya la idea de que el Tratado de 1853 no debe modificarse en ningún caso, idea que se convertirá en el eje de la política española en relación con este asunto. Esta actitud es lógica puesto que dicho tratado concedía ventajas considerables a los españoles.

En el relato de 1856 aparece otro argumento en relación con el problema de los créditos considerados ilegítimos por los mexicanos. Se recurre "al derecho" y a la distinción entre Derecho común y Derecho internacional. El gobierno español considera que no se puede aplicar el Derecho común a los pactos internacionales pues no existe un tribunal superior que dirima los pleitos. Y alega igualmente que si hay errores, se deben a los funcionarios mexicanos y no a los diplomáticos españoles. Los mexicanos, por su parte, acusan retroactivamente a los ministros españoles (concretamente al marqués de la Ribera) de haberse negado en su momento a comprobar uno a uno

33 Para que los créditos fuesen considerados legítimos los acreedores debían ajustarse a una serie de criterios de origen, continuidad y actualidad de la nacionalidad española, lo que no era el caso de bastantes reclamantes españoles que habían aceptado inicialmente la nacionalidad mexicana al producirse la independencia y luego quisieron recuperar la española. Otro problema surgía si el acreedor inicial había vendido sus bonos a un mexicano o a un ciudadano de otra nación, entonces su reclamación no podía ser considerada en los convenios entre México y España. 
los créditos que se iban a incluir en el Tratado de 1853 para asegurarse de que eran legítimos. Con todo, el relato de 1856 hace referencia a las instrucciones del gobierno español en agosto de 1855 en las que se recomienda al ministro español que, "sin retirar la protesta, se limitase a mantener vivo el derecho de los acreedores españoles". Las autoridades españolas admiten ser sensibles al argumento mexicano de que en esos momentos debe concentrarse en vencer la insurrección (protagonizada por los liberales contra Santa Anna). Los españoles son muy conscientes de que si los insurrectos triunfan saldrían seguramente perdiendo aún más. ${ }^{34}$

Mientras tanto las relaciones se complican puesto que el gobierno mexicano se niega a aceptar a Juan Antoine y Zayas como ministro plenipotenciario español por ser quien negoció en su día el convenio de 1851 en el que ya estarían incluidos créditos ilegítimos. Esta negativa plantea un grave problema a las autoridades españolas ya que hay que conseguir a la vez preservar el honor nacional ultrajado por los mexicanos y evitar la ruptura de relaciones en un momento muy complicado para el gobierno progresista español. ${ }^{35}$ El Negociado en 1855 considera que el gobierno español debe aceptar el derecho mexicano a negarse a aceptar a un diplomático para poder a su vez hacer lo mismo. ${ }^{36}$ La solución que propone es que el gobierno español presione al mexicano para conseguir que Zayas sea aceptado pero inmediatamente relevado. En cuanto a los motivos alegados por México para no admitir a Zayas (la inclusión de créditos ilegítimos en el convenio de 1851), el Negociado afirma que constituyen un razonamiento insostenible puesto que la supuesta responsabilidad de tales intrusiones corresponde al ministro mexicano de Estado y no al representante diplomático español. El Negociado no desconoce que esta solución que propugna implica que el gobierno español adopta una política de energía, susceptible de provocar un

34 AMAE, Tratados Negociaciones siglo XIX, TR 102, 001, El negociado de América sobre la cuestión de Méjico, Madrid, Palacio, 29 de noviembre de 1856.

35 Juan Antoine y Zayas había sido ministro plenipotenciario en México de 1849 a 1851-1852 y de nuevo de 1855 a agosto de 1856, con muchos problemas de aceptación por parte de las autoridades mexicanas. En 1855, el gobierno progresista español debe afrontar conspiraciones de los moderados y presiones franco-británicas para participar en la guerra de Crimea contra Rusia; véase mi trabajo inédito presentado para la habilitación a cátedra Les facteurs idéologiques de la politique extérieure de l'Espagne (1847-1863), diciembre 2005, que está en curso de reelaboración para su publicación en forma de libro.

36 A este respecto el negociado recuerda la expulsión del diplomático británico Bulwer en 1848 y pone el ejemplo del representante de Estados Unidos, Soulé, que fue aceptado cuando debiera haber sido rechazado vistas las consecuencias posteriores en la cuestión cubana; véase Les facteurs idéologiques de la politique extérieure de l'Espagne ... 
rompimiento de relaciones, perjudicial a los intereses de los acreedores afectados. Pero, dice, se trata de una cuestión de dignidad a la que deben subordinarse los intereses políticos y, por otra parte, no cree que los acreedores salieran ganando con una política de concesiones puesto que sería un signo de debilidad española y abriría la puerta a otra crisis aún peor. ${ }^{37}$

El director del Negociado, Miguel de los Santos Álvarez, se muestra globalmente de acuerdo con el oficial, pero disiente en lo relativo a la idea de relevar a Zayas en cuanto fuera aceptado por México. Explica que la negativa mexicana es el fruto del resentimiento por el cese de Ramón Lozano. El ministro de Asuntos Exteriores mexicano, Díez de Bonilla, es "pariente o amigo muy íntimo de la familia de la mujer de Lozano, señora mexicana". Si el gobierno español no hace suya la causa de Zayas, ello supondría confesar que el tratado está "lleno de monstruosidades y de infamias". ${ }^{38}$ Por ello, Miguel de los Santos Álvarez opina que hay que mostrarse inflexible y romper incluso las relaciones si México no acepta el nombramiento de Zayas.

Para conocer la evolución del contencioso hay que recurrir al relato de 1856 en el que se detallan las medidas evocadas por el gobierno español a partir de diciembre de 1855. Se encomienda al ministro que reclame con energía y que incluso demande al capitán general de Cuba el envío de fuerzas navales para apoyar los derechos españoles. Esta actitud de firmeza se ve reforzada por las noticias que proporciona Zayas relativas al trato discriminatorio que padecerían los españoles puesto que los mexicanos siguen pagando a los acreedores ingleses. Es en ese contexto cuando se nombra a Miguel de los Santos Álvarez ministro plenipotenciario en México en marzo de 1856. Se le ordena mostrarse enérgico y se alega que el gobierno mexicano consideró en dos ocasiones como legítimos los créditos que ahora declara ilegítimos.

La situación se tensa entre marzo y abril de 1856 cuando la nueva administración mexicana, liberal, revisa los actos y decisiones del gobierno de Santa Anna y suspende los acuerdos, concretamente el de 1853. España está dispuesta a romper relaciones (Miguel de los Santos Álvarez llega a las costas mexicanas con cuatro buques de guerra) pero quiere que la iniciativa de la ruptura sea mexicana. En realidad no se produjo esa ruptura y se acabó aceptando la mediación de Napoleón III aunque especifi-

37 AMAE, Tratados Negociaciones siglo XIX, TR 102, 001, El negociado de América sobre la cuestión de Méjico, Madrid, Palacio, 8 de junio de 1855.

38 Ibidem. 
cando los españoles que no se trata de un arbitraje y que no aceptarán revisión alguna del tratado vigente. La explicación de esta actitud española que combina la amenaza con la aceptación de una mediación es sencilla: en esos momentos es cuando se produce en España la caída del gobierno progresista. Es éste el contexto que permite comprender la actitud de Santos Álvarez (aceptar la revisión de algunos de los créditos litigiosos), pero su conducta será desaprobada en septiembre. Sin entrar en esta cuestión, hay que hacer referencia a la desconfianza de las autoridades españolas ante lo que consideran intromisiones excesivas de Napoleón III en los asuntos internos. ${ }^{39}$

Como en el caso del relato de junio de 1855, el de 1856 finaliza con un informe del director del Negociado del Ministerio de Estado, Lignés y Bardají. En él se plantean tres interrogantes que sintetizan los problemas planteados por la cuestión del pago de la deuda y el director responde a cada uno de ellos para definir la política que hay que seguir. En primer lugar, ¿debe el gobierno consentir la revisión de los créditos solicitada por la República Mexicana? El director responde negativamente alegando que fue el gobierno mexicano quien dio por buenos los créditos.

En segundo lugar, ¿puede el gobierno español permitir que se rompa y se anule completamente el tercer tratado consentido y que ha creado intereses de mucha cuantía, garantizados bajo la custodia de su honor y la firma de la reina de España? La respuesta es igualmente negativa y para justificarla recuerda que España ha consentido múltiples revisiones de los convenios. Recurre igualmente a un argumento de Derecho internacional según el cual la paz de las naciones depende de que se cumplan los tratados internacionales: "los tratados son la legislación de los pueblos. La Potencia que la viola, viola el derecho de gentes que reconoce como sagrada la fe de que los mismos se deriva". ${ }^{40}$ Se aborda aquí la cuestión de la respetabilidad internacional de un Estado que pretenda ser considerado como tal. Esta referencia a la paz y al respeto de los tratados es lógica puesto que se produce en la coyuntura de la negociación de la paz tras la guerra de Crimen. ${ }^{41}$

39 En septiembre de 1856 hay un temor de que Francia termine invadiendo España tras una serie de maniobras destinadas a rodear a España por el norte (desde julio de 1856 y hasta al menos octubre de ese año hay tropas francesas estacionadas a lo largo de los Pirineos) y el sur (norte de África); en Les facteurs idéologiques de la politique extérieure de l'Espagne ....

40 AMAE, Tratados Negociaciones siglo XIX, TR 102, 001, El negociado de América sobre la cuestión de Méjico, Madrid, Palacio, 29 de noviembre de 1856.

41 En la estela del Congreso de París de 1856 y del tratado de paz, se crearon comisiones y se negociaron tratados internacionales sobre varios asuntos. 
En tercer lugar, ¿existen términos hábiles, después de las medidas adoptadas en los últimos meses, para que España desista de exigir el pago de la deuda y del cumplimiento del tratado de 1853? En otros términos, puede el gobierno español dar marcha atrás en su actitud de firmeza? La respuesta del funcionario vuelve a ser negativa por cuestiones de dignidad nacional. Pasa a estudiar la posibilidad del bloqueo militar de los puertos mexicanos como medida para forzar el pago de la deuda y explica que no sería difícil conseguirlo por disponer de fuerzas suficientes. Pero, sobre todo, recuerda que la guerra civil entre liberales y conservadores se mantiene y que "son varios los caudillos que aspiran a la Presidencia", ${ }^{42}$ por lo que se puede suponer que existe la posibilidad de salir beneficiados de esas divisiones como ya había ocurrido en épocas anteriores.

Por último, Pedro Sorela, encargado de negocios de la Legación española en México, afirma que la idea arraigada en ese país es que España jamás dará el paso de usar la fuerza para obtener satisfacción. Y, según Sorela, esta actitud ofensiva de los mexicanos no es particular "al partido avanzado" (es decir, al liberal) pues Díez de Bonilla era conservador y fue el primero en atacar las convenciones españolas. Para él es evidente que tanto los liberales como los conservadores mexicanos consideran que España es un país débil y por eso no respetan los acuerdos mientras que sí que lo hacen cuando se trata de potencias como Inglaterra o Francia. Como ya se ha apuntado al analizar el recurso al argumento del obligado respeto de las leyes internacionales para garantizar la paz, hay que tener muy en cuenta la circunstancia en que se producen estas observaciones que no es otra que la de la negociación de la paz tras la guerra de Crimea. España se había mantenido neutral y no estuvo entonces presente en el Congreso de París. Esta ausencia marcaba aún más la pérdida de rango internacional de la ex metrópoli tras la independencia de Hispanoamérica. Entre 1856 y 1863, los gobiernos españoles intentan que España se reintegre al círculo privilegiado de los países considerados "potencias". ${ }^{43}$ Antonia Pi-Suñer ha mostrado que el volumen de la deuda era considerablemente superior en el caso inglés y que eso justificaba la prioridad dada al pago de la deuda inglesa, por lo que no habría discriminación. Pero lo que está claro es que las potencias utilizan su situación de poder y hegemonía en su propio benefi-

42 AMAE, Tratados Negociaciones siglo XIX, TR 102, 001, El negociado de América sobre la cuestión de Méjico, Madrid, Palacio, 29 de noviembre de 1856. l'Espagne...

43 Véase el trabajo inédito, ya citado, Les facteurs idéologiques de la politique extérieure de 
cio: es el caso de Francia, que cuestiona la legitimidad de esos créditos españoles pero que utilizara el mismo tipo de argumento (el pago de la deuda francesa por parte de México y la negativa de los mexicanos a aceptar la legitimidad de determinadas deudas) como excusa para precipitar el conflicto en 1861-1862 e instaurar un régimen monárquico.

De la lectura de estos dos relatos sobresalen varios elementos de interés. En primer lugar, los gobiernos mexicanos se comprometen a pagar pero, casi inmediatamente después, dejan de cumplir sus obligaciones, bien mediante la suspensión del pago, bien mediante la denuncia del convenio como nulo. Las autoridades españolas reconocen que este comportamiento es común a conservadores y liberales, pero se muestran generalmente mejor dispuestas hacia los primeros, que son quienes han beneficiado reiteradamente a los acreedores españoles, hasta el punto de que, en el verano de 1855, el gobierno español - progresista - dice comprender que la prioridad para el de México es vencer la insurrección y limita sus protestas a un nivel protocolario.

Por otra parte, las redes de relaciones en México de los representantes diplomáticos españoles son muy importantes para esas negociaciones y, junto con las dificultades políticas internas (sublevaciones, guerra de facciones) es preciso tener en cuenta el peso de los intereses particulares de los dirigentes políticos — mexicanos y españoles-, algo denunciado regularmente en las Cámaras mexicanas. Fue el caso, por ejemplo, de Fernando Ramírez, ministro mexicano, o de Bonilla y sus lazos con la mujer de Ramón Lozano. En este asunto de la negativa a recibir al diplomático, la correspondencia muestra la percepción española y las divergencias entre funcionarios. Se ve igualmente la dificultad de separar unos convenios de otros y como se utilizan todos para justificar las exigencias. Se entremezclan cuestiones financieras (la deuda) con aspectos de honor y de salvaguarda de la independencia nacional.

En tercer lugar, los representantes diplomáticos interpretan las instrucciones que han recibido sobre esta cuestión y adoptan decisiones que luego no serán aprobadas por el gobierno español. Fue el caso, por ejemplo, del marqués de la Ribera y en 1856 de Miguel de los Santos Álvarez. Se aprecia igualmente la ambigüedad de las relaciones entre los acreedores españoles (divididos entre sí) y los representantes diplomáticos

En esta cuestión de la deuda se advierte que se maneja la diplomacia oficial y la diplomacia secreta (se incluyen artículos secretos), pero el progresivo afianzamiento del sistema liberal plantea problemas puesto que los 
tratados deben ser aprobados (y por tanto discutidos previamente) por las Cámaras legislativas y que la prensa comenta las decisiones adoptadas. Se ve igualmente cómo se asume lo anterior mediante una alusión indirecta y no mediante una referencia explícita para evitar precisamente el escollo parlamentario y de la opinión (referencias a "aquel" convenio —el de 1851 - cuando se firma el de 1853) y que esto da pie a que los gobiernos españoles consideren que todos ellos son legítimos.

La documentación demuestra igualmente la conciencia española (en noviembre de 1856) de que el tratado de 1853 concede a los acreedores españoles ventajas que no les habían dado ninguno de los convenios anteriores. Esto permite comprender la sintonía entre progresistas y moderados en este asunto del mantenimiento de la validez de dicho tratado. Se aprecia igualmente que a la administración española no le sorprende que el gobierno mexicano no pueda cumplir dicho tratado desde el principio.

\section{¿Los asesinatos de españoles: delito común o guerra de razas?}

A partir de septiembre de 1856, a la cuestión de la deuda, que genera mucha tensión, se une la de los asesinatos de españoles. De nuevo la cuestión del Derecho y de la Justicia se encuentra en el centro del conflicto, siempre en relación con la cuestión de la nacionalidad. En efecto, para mexicanos y españoles es vital determinar si son crímenes comunes, obra de delincuentes movidos por el afán de lucro u otras motivaciones sociales, o si, por el contrario, son actos de persecución racial, es decir, actos políticos con una clarísima voluntad anti-española. En función de la naturaleza común o política del acto se determinará el procedimiento judicial y el tribunal competente para tramitarlo. Si se trata de un episodio de una campaña anti-española se entra en el conflicto internacional y puede servir de excusa para proceder a una intervención militar, lo que pone en peligro la soberanía e independencia de México. Como estos acontecimientos, por una parte excitan la atención de la opinión pública y por su misma índole favorecen las reacciones emotivas y apasionadas y, por otra, se producen en pleno conflicto en torno a la legitimidad o ilegitimidad de los créditos, es grande la tentación de utilizarlos para dirimir el larguísimo contencioso de la deuda que, en cambio, es menos propicio a generar la adhesión emocional de la sociedad española puesto que tiene una dimensión de clase que los asesinatos no tienen. Por eso, desde que se tiene conocimiento de lo suce- 
dido, españoles y mexicanos tratan de determinar si los que encarnan en cada caso la autoridad política - el alcalde, el general Álvare ${ }^{44}$ y sus seguidores - están o no implicados en los asesinatos, y si éstos forman parte de un plan más amplio de "exterminio" de todos los españoles residentes en México. En el limitado espacio de este trabajo resulta imposible analizar pormenorizadamente este contencioso puesto que el conflicto entre los dos países se prolongará por espacio de dos años y dará lugar a una mediación franco-británica. ${ }^{45}$ Se trata de ver cómo actúa el factor "justicia y derecho". ${ }^{46}$

El primer incidente se produce el quince de septiembre de 1856 cuando estalla un motín en el Mineral de San Dimas (Estado de Durango) y, al grito de “¡Mueran los gachupines!”, los amotinados se dirigen a la hacienda de un español, Andrés Castillo, y asesinan al hermano de éste, Juan Castillo. Según el encargado de negocios, Pedro Sorela, la ronda que debía asegurar el orden se unió al motín, lo que demuestra la complicidad del municipio con los amotinados y confiere una naturaleza política y claramente anti-española a los hechos. ${ }^{47}$ Tres meses después, el despacho de 31 de diciembre de 1856 informa que se ha producido un ataque en la hacienda de San Vicente en Cuernavaca, perteneciente al español Pio

44 El general Álvarez no es un "caudillo" cualquiera puesto que fue presidente de la República Mexicana de octubre a diciembre de 1855 antes de pasar el poder a Ignacio Comonfort Controla el Estado de Guerrero y los asesinatos se producen precisamente en los territorios colindantes; véase Falcón, Romana: Las rasgaduras de la descolonización. Españoles y mexicanos a mediados del siglo XIX, El Colegio de México, México, 1997.

45 En otros estudios he analizado aspectos de este contencioso; véase "La question mexicaine au cœur des relations hispano-françaises (1857-1863)", en Journée d'Etudes sur LatinitéAméricanisme-Amériques dirigida por Paul Aubert, Université Aix-Marseille/MMSH, Aix-enProvence, abril de 2005 (en prensa) y "Las relaciones hispano-mexicanas (1856-1863): un ejemplo de los límites y de las ambigüedades de la política exterior española en el reinado de Isabel II”, en XII Encuentro de Latinoamericanistas Españoles, Santander (España), 21-23 de septiembre de 2006. Véase también Pérez Vejo, Tomás: "Hispanofobia y antigachupinismo en la tierra caliente de Morelos: las claves de un conflicto", en Sánchez Andrés, Agustín; Pérez Vejo, Tomás y Landavazo, Marco Antonio (coords.): Imágenes e imaginarios sobre España en México siglos XIX y XX, Editorial Porrúa-IIH de la UMSNH-Conacyt, México, 2007, págs. 99-142.

46 Todo este capítulo se basa en la información proporcionada por un largo expediente del Negociado de América sobre la cuestión de México (fechado en Palacio el cuatro de marzo de 1857 y que relata los sucesos y las decisiones adoptadas hasta inicios de octubre de ese mismo año) y por la correspondencia diplomática que se encuentra incluida en dicho expediente: AMAE, Tratados y Negociaciones siglo XIX, $\mathrm{n}^{\circ} 156$, TR102, expediente 003. Como en ocasiones anteriores, para no multiplicar las notas, sólo se citará específicamente cuando haya cambio de fechas o se considere necesario para evitar confusiones.

47 AMAE, Tratados Negociaciones siglo XIX, TR 102, 001, El negociado de América sobre la cuestión de Méjico, Madrid, Palacio, 29 de noviembre de 1856. 
Bermejillo. ${ }^{48}$ Una partida de unos treinta hombres armados, cuyos jefes iban enmascarados y a los gritos de "¡Viva el General Álvarez y Villalba!” y “imueran los españoles!”, asesinan de la manera más cruel e inhumana a Nicolás Bermejillo, Ignacio de la Tejera, León Aguirre, Víctor Allende y Juan de Bermejillo, de apenas 15 años. Los que se salvan lo consiguen al declarar que no son españoles sino vasco-franceses (Laburru) y anglo-americanos. Bermejillo ofreció cuarenta mil duros por su vida pero ellos lo rechazaron "porque tenían que cumplir su misión de exterminar a los españoles" ${ }^{49}$ Otro elemento que demuestra la implicación directa del general Álvarez es que a los pocos días apareció en Cuernavaca con los caballos robados en San Vicente. Otra hacienda del mismo Bermejillo, Chinconcuaque, fue saqueada unos días después.

Para confirmar la naturaleza racial y política de estos crímenes, el representante español envía una serie de documentos anejos, compuestos por las declaraciones de personalidades extranjeras (el ministro inglés en México, un médico británico de Cuernavaca), mexicanas (el general Haro, comandante general de Cuernavaca; el prefecto de Cuernavaca) y españolas (el vice-cónsul de Cuernavaca). El ministro inglés se refiere a un despacho suyo fechado en agosto de 1856, en el que anunciaba ya la posibilidad de una guerra de razas y, para él, los acontecimientos de San Vicente responden a esa dinámica. El encargado de negocios español, Pedro Sorela, protesta y el ministro de Relaciones Exteriores mexicano, Lerdo de Tejada, responde afirmando que se trata de delitos comunes cometidos por una gavilla de ladrones enmascarados. La correspondencia del diplomático español insiste en que se extienden los rumores por la capital mexicana relativos al inicio inminente de "una atroz persecución contra los españoles" ${ }^{50}$ por parte de las tropas del general Álvarez a las órdenes de algunos oficiales de su confianza. Sorela obtiene el apoyo del cuerpo diplomático, empezando por el decano que es el ministro de Guatemala, que tiene propiedades en Cuernavaca y que confirma el clima de guerra de exterminio contra los españoles. La base de la argumentación española serán los testimonios de personas presentadas como competentes e imparciales, que confirman la tesis de la motivación política del asalto. También se recogen testimonios de otros militares, como el general Haro, quien escribe a Álvarez y atribuye a oficiales de su confianza esos asesinatos.

48 Ibidem, TR102, 003.

49 Ibidem.

50 Ibidem. 
La documentación muestra el intercambio de notas entre Sorela y Lerdo de Tejada y cómo al principio el Gobierno mexicano cuenta que ha pedido a Álvarez la entrega de los oficiales culpables pero que éste se resiste a ello. Aparece desde el principio una dualidad entre los testimonios que implican verbalmente a los oficiales de Álvarez y la falta de reconocimiento oficial y por escrito de esas mismas acusaciones contra Álvarez. Sorela se muestra convencido de que el gobierno mexicano presidido por Comonfort no se enfrentará nunca a quien domina realmente México. Se llega muy pronto a la ruptura de relaciones, en enero de 1857 . Y las autoridades españolas analizan la posibilidad de enviar buques de guerra a las costas mexicanas. A este respecto, el capitán general de Cuba, el general de la Concha, está dispuesto a hacerlo y asegura que la seguridad de la Isla no peligrará por ello.

Sin embargo, es interesante ver cómo De la Concha, en fechas tempranas (once de enero de 1857), desestima la tesis del ministro inglés sobre el inicio de una guerra de razas lanzada por el general Álvarez, impulsado a su vez por Estados Unidos para obligar a México a solicitar el protectorado estadounidense ${ }^{51}$ Prudente, De la Concha no niega tal eventualidad, pero opina que los sucesos de Cuernavaca y de San Vicente son el resultado, por una parte, de la extrema debilidad y del estado de disolución y anarquía en que se encuentra México y, por otra, de la posición especial en que desde hace mucho tiempo se halla colocado el general Álvarez, en el sentido de ser el árbitro frente a cualquier intento de consolidación de un gobierno respetable en dicho país. Opina que la estrategia de Álvarez consiste en conservar y ampliar el territorio bajo su control y, por tanto, el objetivo en ese momento sería la anexión de Cuernavaca al territorio de Guerrero. Ante la negativa del Congreso mexicano a tal unión, la respuesta sería la amenaza y los asesinatos, una demostración de la voluntad de lograr esa anexión por todos los medios a su alcance. Para De la Concha, si no se producen otros asesinatos de españoles en distintos puntos de la República, se confirmaría que no se trata de una guerra de razas sino de una lucha de facciones. Insiste el capitán general de Cuba en que importa mucho que el gobierno español comprenda de qué se trata exactamente (si de una guerra de razas o no) antes de adoptar una determinada estrategia.

El general de la Concha defiende pues que no se trata de una guerra de exterminio contra los españoles y que eso permite considerar la posibi-

51 Ibidem. El capitán general de Cuba, De la Concha, a Estado, 11 de enero de 1857. 
lidad de actuar con firmeza recurriendo al uso de la fuerza. Se trata de ocupar o de atacar uno o dos puntos importantes del litoral, lo que propiciaría la caída del gobierno de Comonfort y la formación de uno nuevo que accedería a las demandas españolas. De la Concha propone ocupar Acapulco y la costa sur del Pacífico, lo cual serviría para castigar a Álvarez y para impedir que pudiera ayudar a Comonfort. El otro punto que debe ser tomado es Veracruz y el Castillo de San Juan de Ulúa para "que se tuviese en su justa apreciación las fuerzas y los medios con que cuenta España y hacer olvidar la expedición de Barradas, además de distraer hacia esa parte las fuerzas de Comonfort, lo que facilitaría que sus enemigos lo arrojasen del poder"..$^{52}$

Sorela se entrevista con los representantes francés e inglés y en su despacho del veintidós de enero de 1857, antes de abandonar México, da cuenta de la conducta tan diferente de los representantes de ambas potencias El ministro francés, Gabriac, critica abiertamente el ultimátum español y la ruptura de relaciones, actitud que, en opinión de Sorela, no corresponde a una potencia estrechamente aliada de España. En cambio, el ministro inglés declara que para su gobierno la matanza en sí no sería considerada como un agravio, pero sí la tardanza en detener y castigar a los culpables. Para explicar la actitud del ministro francés, Sorela cita la opinión de personas respetables que indican que Gabriac fomentaría la ruptura entre España y México para luego ser el actor central del arreglo del conflicto. Resurge entonces a la cuestión del paternalismo galo que ya apuntamos anteriormente. $\mathrm{Y}$ en contraste con esta actitud francesa, Inglaterra apoya a España siempre que imperen la razón y la justicia. Esta valoración de las intenciones francesas se confirma con los informes de Serrano, embajador en París, y de González Brabo en Londres, puesto que ambos indican que Napoleón III ofrece su mediación y pide prudencia a España, alegando el peligro de desencadenar una guerra con Estados Unidos y de perder entonces el dominio de Cuba.

A medida que pasan los días, el asunto evoluciona pues ya no se trata de demostrar que es una campaña política de exterminio de los españoles, sino que se exige la detención y el castigo de los culpables. La controversia se desplaza entonces hacia la capacidad de México para impartir justicia: los mexicanos alegan que hay que respetar las leyes, los procedimientos judiciales previstos por la Constitución mexicana (derecho a ser

52 Ibidem. 
juzgado para ser castigado) y demuestran su buena voluntad al nombrar a un magistrado especial. Además de la cuestión del procedimiento judicial (respeto por la organización judicial mexicana), las autoridades españolas exigen que los mexicanos indemnicen a las víctimas, pretensión rechazada por su gobierno que afirma que es un hecho casual y que sólo cabría indemnizar si el gobierno hubiera sido cómplice de los delitos. Se cierra entonces el círculo que había comenzado con la cuestión de si se trataba o no de una guerra de razas, es decir, de una campaña política y premeditada de exterminio de los españoles, y se llega al final al mismo asunto de la justicia y el castigo de los culpables, pero pasando por la exigencia española de obtener reparación e indemnización pecuniaria. Y esta cuestión de la indemnización permitirá unir dos asuntos en principio muy alejados el uno del otro: el problema de los crímenes y el de la deuda.

A medida que transcurren los días y los meses, el contencioso se complica por supuestas injerencias francesas que provocan que el enviado mexicano, Lafragua, permanezca en París en lugar de desplazarse a Madrid para solucionar los dos asuntos, el de las indemnizaciones y el de la deuda. Por otra parte, el ministro de Marina envía un despacho al ministro de Estado, el marqués de Pidal, el veinticuatro de febrero de 1857 en el que indica que Pío Bermejillo, la víctima de los sucesos de diciembre de 1856, es uno de "los muchos españoles que para lograr negocios ingentes no ha titubeado en adherirse a partidos políticos, que ha sido íntimo amigo de Santa Anna, que ha hecho empréstitos y anticipaciones y que así ha reunido grandes propiedades rústicas y muy crecido capital". ${ }^{33}$ El cambio de actitud es considerable: de denunciar una injusta guerra de exterminio y unos crímenes sin sentido ni motivo, se pasa a responsabilizar en parte a las mismas víctimas de lo sucedido. Este informe coincide con un cambio de actitud por parte de las autoridades españolas, que afirman que los buques van únicamente a proteger a los españoles y no a ocupar México.

Para comprender estos cambios, es preciso señalar que interfieren los acontecimientos políticos que se producen en México, entre los cuales cabe destacar la rebelión de Vidaurre contra Comonfort y el miedo a que Estados Unidos aproveche la ocasión para ofrecer ayuda financiera a cambio de territorio. Esto explica el cambio de actitud de De la Concha que, en febrero de 1857, afirma que España debe apoyar a Comonfort pues si éste fuese derrocado se llegaría a la desorganización total del país y aumentaría el

53 Ibidem, TR 102, 003. 
peligro de control de Estados Unidos. Este temor aumenta a partir de marzo pues se perfila la posibilidad de que Estados Unidos obtenga la construcción del ferrocarril entre Veracruz y Nueva Orleans, línea que podría ser utilizada con fines militares contra Cuba. También aparece el argumento de la decadencia de la raza latina y del auge anglo-sajón, lo que se traduce, según el marqués de la Ribera desde Berlín, en las simpatías alemanas para con los Estados Unidos y su política de expansión.En junio de 1857 Lafragua remite las propuestas mexicanas en medio de las ofertas mediadoras de ingleses y franceses, que advierten que no apoyarán a España si estalla un conflicto con Estados Unidos como consecuencia de la tensión con México y si dicho conflicto acarrea la pérdida de Cuba. En primer lugar, el gobierno mexicano seguirá haciendo lo posible para castigar a los culpables. Si en el juicio se probase que había intervenido alguna autoridad, se aceptaría la exigencia de indemnizar, pero el acuerdo se haría bajo los auspicios de la reina de Inglaterra. En lo relativo a la deuda, se cumpliría el tratado de 1853, pero nombrando una comisión encargada de revisar los créditos y que estaría compuesta por un mexicano, un español y un tercer miembro nombrado por los españoles y mexicanos o, en su defecto, por el ministro francés en México. La respuesta española en julio consiste en aceptar la mediación franco-británica, pero únicamente como medio para obtener las debidas reparaciones por vía pacífica en lugar de recurrir a las armas.

Antes de poner fin a su misión, Lafragua envía a fines de julio un memorándum en el que constata el cambio de las exigencias españolas entre marzo y julio de 1857. En marzo, dice, no se hablaba del tratado de 1853 ni de la indemnización de las víctimas como condición previa, sino que se hablaba de campaña política de exterminio de los españoles y no se extendía la indemnización a todos los casos (sólo se hablaba de San Vicente). En cambio, en julio se habla del tratado de la deuda y de indemnización general de todas las víctimas españolas y no sólo de las de los asesinatos de San Vicente.

Tras una larga mediación, que no produce resultados concretos, y como consecuencia del estallido de la guerra de Reforma en México, España llega en 1859 a un acuerdo con los conservadores mexicanos que dominan una parte del país y se firma un tratado -el conocido como MonAlmonte- en el que se arregla la cuestión en beneficio de España. El general de la Concha opina entonces que ha sido un error mezclar las diferentes cuestiones y firmar ese acuerdo con los conservadores porque considera 
que van a perder la guerra y que habría habido que separar la cuestión de la deuda de todo lo demás. La evolución de los acontecimientos demostrará que su visión era acertada.

\section{A modo de conclusión}

El estudio de estas tres cuestiones —el tratado de extradición, la deuda y los asesinatos de españoles - ha permitido, por una parte, destacar la importancia de la justicia en las relaciones hispano-mexicanas y su relación estrecha con el concepto de nacionalidad, y, por otra, ver cómo cada país utiliza el argumento del "derecho" — nacional para unos, internacional para los otros - para defender sus intereses. Sin embargo, ese recurso al Derecho y, por tanto, a la noción de interés público superior, no se corresponde con la realidad puesto que, en la práctica, no se deslinda lo privado de lo público, ni lo nacional de lo extranjero, como lo demuestran las connivencias entre los políticos mexicanos y los representantes españoles y entre los acreedores españoles y los mexicanos, tanto los políticos como los miembros de la elite económica y financiera. Se aprecia claramente que es un periodo de construcción del Estado-nación, de extensión de los principios liberales de superioridad de la ley y de igualdad de todos ante esa misma ley, de definición de la identidad nacional y de lo que podría llamarse una "política de Estado".

Por otra parte, se puede afirmar que globalmente México salió airoso, aunque en ocasiones más por la evolución de los acontecimientos que por la voluntad de sus dirigentes. Y que ese "triunfo" supone una acción -muy incipiente ciertamente- a favor de la ampliación del concierto internacional (antes limitado a unos cuantos Estados europeos) y de la creación de una auténtica "sociedad internacional". En efecto, no se llegó a ratificar el tratado de extradición propuesto por Salvador Bermúdez de Castro y que incluía la extradición por motivos políticos, algo más en la línea del Antiguo Régimen que del sistema liberal. Además de los cambios de gobierno en México, las revoluciones de 1848, con su radicalización social y política, favorecen la adopción de determinados principios liberales rechazados hasta entonces por considerarse que es mejor un liberalismo moderado al triunfo de la revolución "socialista". Uno de ellos es el derecho de asilo que es el reverso del principio de extradición por motivos políticos. En cuanto a la cuestión de la deuda y de los asesinatos, de nuevo 
México logra evitar tanto la intervención militar como el pago efectivo mediante la estrategia de utilizar las rivalidades entre las potencias y de presentar a España como un país decadente y débil. Defiende la validez y la competencia de sus leyes y de sus tribunales, con lo que se reafirma como Estado independiente y soberano.

Desde el punto de vista español, se aprecia el peso de las divisiones entre el personal político y diplomático (determinadas decisiones no son unánimemente aceptadas). Pero se ve igualmente la importancia de la red de relaciones entre los diplomáticos españoles y la clase política mexicana. Los informes analizados han permitido, por otra parte, distinguir el discurso de uso "externo y oficial" del discurso "interno y confidencial". Los diplomáticos y dirigentes españoles son plenamente conscientes de la falta de "justicia" y de legitimidad de algunas reclamaciones (concretamente las relativas a la deuda) y de las exageraciones y manipulaciones de la realidad por parte de algunos personajes (en el caso de la supuesta campaña de exterminio). Esto permite comprender mejor lo que en apariencia podría considerarse como vacilaciones y contradicciones. En realidad se trata de la falta de deslinde entre los intereses privados y los públicos. Por último, los dirigentes españoles apelan al "Derecho internacional" y aceptan el arbitraje, conscientes de su debilidad y de la falta de medios militares y económicos para, por una parte, imponer a los mexicanos sus "derechos" o sus "voluntades" por la fuerza y, por otra, resistir a las presiones y a las ambiciones de hegemonía de Francia. Contribuyen entonces igualmente a la consolidación de un espacio público internacional, aunque como ya se ha indicado sólo sean las premisas de ese proceso.

Recibido el 14 de octubre de 2008 Aceptado el 7 de enero de 2009 